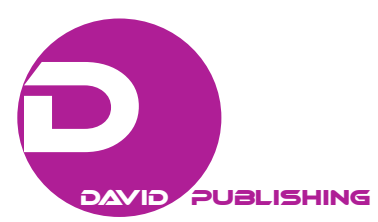

\title{
Internet Through Mobile Phone and Its Cognitive and Behavioral Impact: Changing Sexuality*
}

\author{
Manoj Jinadasa \\ University of Kelaniya, Kelaniya, Sri Lanka
}

\begin{abstract}
This study investigates how Internet media in the mobile phone influence on the cognitive and behavioral aspects of human sexuality. Sex is being deviating from socially accepted behaviors; ranging from bisexuality to homosexuality. Based on the qualitative methodology using particular case studies and textual analysis as well as survey research leading to quantitative methodology, this assumes of a transition of cultures as a result of the thorough impact of Internet towards society. In conclusion, Internet implicit practices in the Mobile Phone in youth and teen societies storms a big change in sexuality, is also affecting towards the human cognitive and behavioral phases of the social life in traditional Buddhist rural village setting in Sri Lanka.
\end{abstract}

Keywords: Mobile phone-Internet, changing sexuality, cognitive and behavioral impact, Buddhist rural society, youth and teen

Impact of Internet media and mobile phone on youth sexuality has been concerned by many scholars (Livingstone, 1999; Flanagin \& Metzger, 2001; Wei \& Lo, 2013. See Pascoe, 2011; Ringrose et al., 2012). This study was to identify the ill-effects of mobile phone usage in the rural Buddhist societies in Sri Lanka. In this, it was focused to investigate about the phase of teen and youth behavior in usage of Internet through mobile phone. Internet mobile phone impact can be studies on the basis of cognitive and behavioral changing patterns. In such a broad perspective, this study focused to scrutinize on the changing pattern of sexuality among teen and youth who are highly exposed to Internet mobile phone. In that, the most interesting fact is that the sexuality has been changed from the heterosexual behaviors to bisexual and homosexual activities among the subjects.

Young people are commonly assumed to be highly susceptible to the influence of the mass media, which have been blamed for a number of negative cognitive and behavioral influences (Annenberg Media Exposure Research Group, 2008). Computers, video games, and the advent of the World Wide Web have been considered potentially damaging to youth. In spite of the generally held belief that media act as vehicles of persuasion, there are only mixed results linking exposure to media with various cognitive and behavioral outcomes. Some studies have found evidence for substantial media effects, while others have not (Klapper, 1960). In a more

\footnotetext{
*Acknowledgement: This research has been sustained by the two research projects to which funded by the University of Kelaniya, Kelaniya, Sri Lanka. One was granted by the Annual Research grant fund of the University of Kelaniya and the other was granted by the center for Social Sciences Research, faculty of Social Sciences, University of Kelaniya, Kelaniya, Sri Lanka. I am totally indebted to the labour made by my research students in last couples of years from whom I grasped many information from different perspectives so that finally I was possible to see them in a more broad framework of analysis. Special gratitude is deserved for the anonymous reviewers of this paper.

Manoj Jinadasa, MSSc, Senior Lecturer, Department of Mass Communication, Faculty of Social Sciences, University of Kelaniya.
} 
social anthropological perspective that understand this prevailing situation emerges a contradiction in social and cognitive behaviors in the rural Buddhist villagers lifestyles and at the phase of how they have been practiced for many decades by a realistic Buddhist philosophical religion. In this, it was peculiarly visible of a more contradiction of the real practice of religion and the way how modern new media man adapt and apt with the new media society that is full of consumer and liberty in the social-culture and political-economy, so that this assume of a more open and unlimited social and cognitive behaviors at the phase of delimited information flow and high access to them in any physical or spatial place in the use of Internet through mobile phone.

In other words, this social change expresses that the social ethics and ambitions generated in the well-sophisticated and realistic religious cultures that deeply rooted in the pre-media society could not have possible to manage this modern new media society. As a result of this, it is crystal clear about the shift of paradigm in the sexuality at the phase of youth cognitive and behavioral changings. However, this has given a much debatable and burning issue of the fact that how Buddhist cultured rural villagers socially and morally accept this sexual deviation; ranging from Bisexuality to Homosexuality. There are many incidents and cases have been reported as the unpleasant criminal or discriminative social behaviors in this sexuality change. Even though, it is not the fact that Internet media is not the one and only catalyst in this phenomena, however this has open for many illicit and socially unacceptable contents of sexualities and personal entertainment. Therefore relevance and importance of furthering our media and communication research on this social change created in the usage of Internet mobile phone in rural Buddhist villagers' cultures has been taking into significant importance.

Moreover, even though it is highly appreciated of a long existing Buddhist educational system derived out from piriwena; a monastic educational school from rural village to urban places and the long historical evidence coincides in local religious practices in the Buddhist precept and discipline, accelerating number of crime and murder with huge social destruction at the phases of family and society could be more explicit in the modern new media cultural society.

Hence, it is our concern to draw the attention on to explore whether youth is moving towards socially unaccepted illicit sexual patterns that is contradictory with the Buddhist religious practice in the phase of Internet usage using highly expanding Mobile Phone.

\section{Materials and Methods}

\section{Research Problem, Hypothesis and Research Questions}

In this study, the fundamental problem of research is: How do Internet mobile phone effect on changing sexuality from heterosexuality to socially unaccepted behaviors (bisexuality and homosexuality) in the rural Buddhist societies in Sri Lanka?

So that the assumption made in the literary review is: Internet mobile phone has given a much platform to express and activate hidden sexual desires and behaviors among the adolescents and youth even though they have long been highly taught and practiced in Buddhist religion in local rural societies.

However, this has created to extend the sexuality from normative traditions to bisexuality and particularly to homosexuality. As the fear and social deprivation, the new sexual orientations made by this situation, are practicing in implicit ways, while in the dominant religious thought has not been given attention to this effects. Moreover, this social change that is deeply associated with the sexual behaviors and new media effects on the conventional religious societies has not been properly addressed by either religious or academic discussions in 
Sri Lanka. On the contrary, an interesting social and cultural contradiction is rapidly increasing in the rate of sexual problems in the family, divorce rate, sexual crime, other crime and murder in a more religious practicing society which is highly ethical and civilized according to popular religious talking and preaching.

None of the academic or religious school has paid yet their attention on this social destruction in a cognitive and behavioral perspective. Hence, this has been given a contemporary relevance and importance as the immediate effects of Internet and mobile phone are emanating to the society as their use rate is also increasing day by day. So, amidst the new media under a high consumer and open economy society has led to this cultural and moral changing pattern. In other words, while we talk about a highly sophisticated, most cultured and civilized religious practice of life in the realm of Buddhism, we have to face to a most challenging social and cultural life that constitutes many socially unacceptable and culturally in tolerable events and incidents of sexual deviations, criminal offenders, that leads to a huge destruction of the social system of the organizational malfunction in the Sri Lankan Society.

In this hypothetical framework, this study is addressing following research questions:

(1) Does Internet effect on changing sexuality? If so, how does it occur in the use of Internet Mobile Phone?

(2) Do the changes of human sexuality correlate with the Internet using via Mobile Phone? If so, how does it work in the practice?

(3) How does Buddhist rural society really respond to new media cultures? What are the effects of Internet mobile Phone related to human sexuality?

(4) Why do the rate of crime, murder, sexual problems and other family destructions rapidly increase amidst the most Buddhist religious media and communication society?

(5) Do widely expanding communication and media of Buddhist religious practices not having relationship with increasing social changes in the facets of sexuality? If so what are the other issues related to sexual changes?

\section{Research Methodology}

This study carried out using qualitative and quantitative mixed perspective including survey (questionnaire), case study (participatory and Non-participatory Observation, In-depth and Focused-group Interviewing) and textual analysis (Observation, Interviewing, reading, interaction).

Survey was done using questionnaire and personal interviewing that raised fifteen (15) questions and questionnaire was distributed among 200 subjects representing geographical and demographical dimensions associated with the research problem using convenient sampling. Age categories are 14-16, 17-19, 20-25, and 26-30 covering youth and adolescents in the Buddhist rural societies.

Five (05) case studies were conducted covering rural Buddhist societies refers to the effects of Internet mobile phone on their sexualities over the last couple of years (2011-2014). These cases were more related to sexualities ranging from hetero to Bi. and Homo. Basically these cases were identified from Newspapers and thereafter cases were fully investigated using from police reports, participatory observations, in-depth Interviews and focused group discussions serially.

Textual analysis was used to further read some of the Internet texts and mobile phone texts associating to their behaviors of using new media in their personal life. For this, twenty five (25) fake FB (Facebook) addresses were made and gather information of how they communicate and what they communicate. And 
another twentyfive (25) personal interviews were made to identify how adolescents and youth use Internet for their sexual gratification and contentions through mobile phone.

However, this overall methods and materials were limited to age category of 14 to 35 including substantial representation of gender, geography, age, culture, religion, associated to the fundamental research question. The study occurred during a period of twenty four (24) months.

\section{Ethical Considerations}

All the subjects were previously being acknowledged, informed and aware of the purpose of being selection of their subjective behaviors, attitudes and opinions of their sexualities, so that consent has been granted through this formal acknowledgement before gathering data from them. Personal names were not applied for the data collection methods and data analysis techniques. None of the subjects were used without prior consent made by the key research officer.

And the gathered information was analyzed for this research study only and not being distributed or revealed to any other third party. Part of the data collection is associated with my another research titled The expansion of pornography through new media, which was institutionally granted by the annual research grant program of the University of Kelaniya, Sri Lanka. In that, institutional formal ethical permission has also been made by the University of Kelaniya, Sri Lanka.

\section{Limitations of the Study}

This study is focused merely to impact of Internet mobile phone on changing sexuality. In that study focused to limit on adolescents and youth. In the sense of sexuality change, it is given much attention on bisexuality and homosexuality. In this, the contradiction of Buddhist preaching and rapidly increasing rate of crime, murder, sexual problems, and socially unacceptable sexualities is given much concentration.

In identifying implicit behaviors of sexuality, it was hard to investigate true and natural gratifications and entertainment in the use of Internet via mobile phone in the data collection method of questionnaire, so that using interviewing and observation have been given considerable affording to fill this vacuum. As the sexuality being the most dominant aspect of privacy and personal matters, collected data could have been mixed with certain subjective values and norms more than objective aspects of the research analysis. In the content of fake Facebook addresses, there might be certain false response to our requests. Even in the analysis of texts of their usage of Internet forms in the mobile phone many real objective facts were not possible to collect as them being the behind of the barriers of privacy and personal gratification.

\section{Results}

\section{Survey}

Questionnaires were given to 200 subjects $(n=200)$. Age frame is from 14 to 30 , consisting similar $32.5 \%$ in both 14-16 and 20-25 age categories. And 17.5\% in both 17-19 and 20-25 age categories as being the same percentage. Gender representation is included as male and female by 90 and 110 respectively to the percentage of population.

$39 \%$ of the subjects use Mobile Phone for the Internet while another $40.5 \%$ use Computer for the Internet. Thus, almost $79.5 \%$ use Internet significantly, while another $20.5 \%$ do use Internet neither from computer nor Mobile phone. However, the fact that these non-users of Internet are interested to see pornography contents, which are downloaded from the internet, is also important in this context. 
Entertainment has been the most interesting Internet content by $89 \%$, while Internet use for educational purposes is $61 \%$ which is being the second priority in the serial order of Internet consumer. As in the Table 4 depicts (see the Appendix) Educational content is the most interesting feature of the Internet using by 47\%, which is the most highest rate and it represents from the age category of $20-25$, while $12 \%$, which is the minimal percentage of the most interested Internet content of using in every contents. On the other, entertainment content as being the most popularly expanded content of Internet using in each age category expanding from a similar percentage. However, $29 \%$, which is the maximum is shown in the age category of $17-19$, while $23 \%$ in the age category of 26-30, which is the minimal in entertainment content in the Internet using.

In the overall, male is the maximum by $96 \%$ who use Internet in mobile phone for the sexual gratifications, while another $74 \%$, is female for the same purpose. When it comes to the Internet for pornography, there are several forms of Internet media; web pages of erotica and pornography, Facebook porn contents and using Web cam for pornography behaviors have been popularly used by $67 \%, 38 \%$, and $33 \%$ respectively.

\section{Case Study}

There were five (05) case studies in this research. The cases were reported first in the national newspapers in Sri Lanka. Then, they were separately identified. In order to investigate further, method of In-depth Interview was used in considerable time with the subject and received from his/her associates' ideas and opinions in addition to other observational information produced.

Ampara District (Eastern province) same-sex incident. Children used to watch CD films of pornography when their parents were in faddy field. Two school boys who were having very much attention on pornography film got the chance to enter to such contents in the Internet through their mobile phone. They were both fifteen years old. Gradually they were being interested to watch different forms of sexual activities in the Internet so that they got used to watchsame-sex (gay) web sites in the net from which first they felt quite uncomfortable but later on the basis of increasing aptitude emanated, they were reluctantly addicted to same-sex behaviors by touching their male genitals first. By the time pass, they felt that this sexual behavior enthrall them very much more than their previous masturbation practice. Increasingly they just experienced of anal sex first and later they experimented oral sex and with their new different sexual pattern they needed to search most updated version of the gay web sites from which they having much sexual pleasure. Finally they were caught by the police as the complaint made by their one of the closest friend in the same old. They have been grown in a traditional Buddhist rural village from their early childhood. Despite the police inquiry they feel now much comfort in engaging such kind of same sexual behaviors as they are updated with most recent gay web pages, whilst they are having better sexual stimulation from watching such Internet web pages via mobile phone .

Kandyboys' College (Central province) two teens. First they identified as the friends of same hostel in the school. They were heavy Internet addicts, who chat and web cam with many other peers as well as elders. In the hostels in their isolation after school, they were used to practice sports in the playground from where they talk secret illicit sexual behaviors with peers. First they felt ashamed with each other and later on the understanding of each perception at the phase of such contents and talks, they were reluctantly being absorbed the stimulation of such peer talks. As a result of their on-going sexual talks, they found easy ways of stimulation from their own gender as Internet remains consistent in gay web sites in one hand and on the other, via mobile phone in addition to watching such web contents they were used to chat via FB their secret implicit sexual desires. They are not gays in born but they have transformed their easy sexual gratifications from these 
easy contents of sexual behaviors that are widely expanded in the Internet so that using individual mobile phone gave them to extent their secret behaviors. Finally they were unable to deprive from their practice. One day school principle received massage of this secret relationship from one of the hostel students. However, the principle had to channel a psychiatric medical doctor to consult them despite their arbitrariness.

Two adolescent girls from Kegalle (Sabaragamuwa province). One day the district psychiatric doctor was consulted by two parents from two families of their two daughters that they were having an extraordinary relationship between each other for couple of years. One is so beautiful and the other is quite fat and black in skin-color. That the fat girl is quite hard to control her feeling in the mid night so that she goes to others home in the mid night when her parent went to sleep. She entered to other's room through window secretly. They were falling in a strong love affair as they were using to enthrall each other by web cam their secret places through Internet earlier. First they communicated via the Internet chatting of FB and later they used web cam for their same-sex behaviors. Basically, they have been both fully grown amidst the Buddhist religious cultures from their early childhood.

One youth and another teen (Northern Province). They found from the FB basically in the chatting and later talked about many things and among them their personal sexuality has been the major event so that the FB provides them a platform to exchange their individual ideas and opinions related to privacy and sexual habits, from which their sexual orientation determined finally. Earlier that the youth had a girlfriend in his university but she got revealed his sexual desires for same sex partners. Meanwhile, this youth found a very handsome teen via FB. First they had communication of their sexual activities from the Internet and later they had more chances and opportunities of having more and more same-sex seen and tube videos from the plethora of Internet contents. Both of them are having most updated mobile technological phones are android smart phones from which they able to engage in a variety of sexual contents; exceeding heterosexual contents to Bi and Homo contents. They had unbearable satisfaction from this same sex opportunities found in the net linked mobile phone. Consequently, that the youth guy has some heterosexual behaviors in real world addition to his same sex opportunities.

One teen from prestigious college addicted to internet pornography (Western province). This school teen, who was isolated in his family as he was the one and only child to his parent. Meanwhile his father was also not in the home as he was engaged in a foreign work company so that the mother who has caring and loving to his only child unlimitedly. In this venture, the child used to work under his mother's full love and caring in which he enthralled very much avoiding even in doing his own work without his mother's labor. Hence, this child always plugged in the Internet all over the day and time after the school and other weekends in his own room locking the door. From the very first, when he engaged to Internet through his room computer he was nearly 14 years old. And after a two years period when he was fully abducted by the noose of Internet sex via most updated android smart mobile phone. He was finally channeled to a psychiatric medical doctor as being suffering severely from high Internet pornography addiction. He used to masturbate from watching this pornography content earlier. But later on his performance affected by the Internet porn web pages, he was impossible to detract from them.

\section{Textual Analysis}

Textual analysis was used to further read some of the Internet texts and mobile phone texts associating to their behavior of using new media in their personal life. For this, twenty five (25) fake FB (Facebook) 
addresses were made and gather information from them to know of how they communicate, what they communicate. And another twenty five (25) personal interviews were made to identify how adolescents and youth use Internet for their sexual gratification and contents through mobile phone.

Further, In order to scrutinize some of the implicit sexual behaviors associating with the Internet and mobile phone, participatory observation was used at the places of public toilets in the major cities and couple of school and university toilets.

First, when we concern on the texts of the fake FB which were expressive in very important features related to how adolescents and youth gradually getting into their on line dating and particularly of their real sexual cognition and behaviors. In this, one of the major findings is that the FB has been a platform to play their socially unacceptable sexual desires in a more liberal manner so that in addition to heterosexual intercourse, romantic male sexual desires are also activating from this and finally perhaps they were being enjoying with both sexual behaviors (bisexual behaviors). At the same time, it was understood that many FB users are also being gratified their sexual taste via hidden/fake FB addresses, so that they use other forms of Internet; embark on web cam and chatting to extent their ideas into real practical incident.

In many times, it is more elusive of that large number of teens and youth naturally get into sexual ideas and thoughts leading to their high growth of biological metabolism. However, Internet and mobile phone freedom has been catalyzing them into more communicative sexual behaviors despite the social and cultural norms and morals.

Another result is that the FB has been used by some of the elder people to noose teens and youth people for their sexual behaviors illicitly. In that, these adolescents are also having fake FB and another fake e-mails to hire them for money so that Internet has being a major commercial market for sex in bridging these both elders and adolescents including teens for this implicit sexual panoramas and from them to real sexual practices exceeding traditional sexual behaviors.

And in the personal interviews, it was understood that many teens and youth people have been very quiet and calm in their external appearances. But in practice they have many strategic behaviors leading to use of the Internet through mobile phone for their illicit sexual behaviors. And also gay and lesbian people that useimmensely mobile phone with Internet connection for activating their sexual orientation amidst the sarcastic criticism of dominant sexual thought. They perceive a substantial liberation in the sexual behavior in Internet and mobile phone more than the other traditional media (Press, TV, Radio, Magazine, Film).

In our observation in the public toilets of the major cities of Colombo, Kandy, Kurunegala, Galle and Anuradhapura, one of the interesting features was the fact that many teens and elders were used to write down their mobile phone numbers in the walls requesting to call them for sexual association and implicit intimacy. In this, maximum numbers of wall writers' requests were for seeking adolescents and elders. Men to men sex are more popular in the toilet scriptures. Many writings in the wall depict of a huge interesting for oral sex and anal sex more than other heterosexual behaviors. Thisis very elusive in the signs and symbols depicted in the toilets not only in the public cities but also in the school and university toilets scriptures.

In association with the language use in these wall scriptures, it is crystal clear of the very relationship with the mobile phone short written sign language. Top, Bottom, ... in English and mata oyage eka uranda asai... (I like to suck your penis...), mama sudu malli kenekuta kamati... (I like to have a white color skin teen), wayasa aurudu 15-24 sudu lassana kollekuge uranda asai... (I like to suck of a beautiful boy aged 15-24), gahaganda asai... (like to been fuck), api 69 karamu... (we will do 69) are some of the most popular language used in both 
FB communication and public toilet wall writings that depicts of a more romantic and erotic cognitive and behavioral aspects of language using.

In the video and pictures associating to these sexualities were also so figurative and artful in the nature. In both gay and lesbian sexual communication, they used to apply on the handsome male figures and beautiful girlish pictures and videos in both same-sexual behaviors.

\section{Discussion}

Despite the immense Buddhist religious thought persistent for years in the country and other modes of Buddhist media (TV, Radio, Newspaper) including increasing number of currently popular Buddhist monastics and temples that leads to a very modern type of Buddhist religious movement and practice including many religious, racial, and ethnic struggles, lots of social intolerances and sexual \& mortal crimes are mushrooming over the country. In this study, it was focused to locate them in the place that existing huge Internet influences on societal and cultural change exceeding traditional norms, values and morals. In this, highly expanding communication tool is Mobile phone with the Internet and sexuality change leading to Bisexual and same sex priorities have been the key focal research domain in this study.

In order to discuss the fundamental research problem and the assumption made upon it, first, basic research questions are addressed in this discussion.

(1) Does Internet effect on changing sexuality? If so, how does it occur in the use of Internet Mobile Phone?

According to the survey data analysis in Table 2 (Appendix), it mentions $79.5 \%$ of the subjects use Internet and Table 3 (Appendix) notes that $89 \%$ of those Internet users use Internet for entertainment purposes. Out of this, male receive maximum in Internet using through mobile phone for sexual purposes is $96 \%$ and another $74 \%$ is female who use the same purpose. Conceptual and operational definition of terms is a prerequisite to scientific discussion and research concerning sexually implicit materials, on or off the Internet. A three-part conceptualization of erotica, degrading pornography, and violent pornography has been suggested to guide theory and research in this area.

The Internet opens new opportunities for families but it also poses a challenge to current forms of family interaction and the organization of everyday life. Teenagers have been found to use the Internet more than do adults and there is also a tendency for homes containing older children to have greater Internet access (Livingstoneet al., 1999). In younger age groups, only a small proportions are regular users of e-mail and Internet, but the services are well-known to most children (Beentjes et al., 1999).

As a controversial and morally-loaded issue, homosexuality has often sparked heated debates (Gross, 1991; Ho \& McLeod, 2008). While these debates have been most prominent in Western countries, disputes over homosexuality's significance in society and its regulation are becoming more common in Asia (Detenber, Cenite, Zhou, \& Malik, 2009). Often the debates focus on the portrayals of homosexuality in the media, and the influence they may have on impressionable populations. Since media content can be seen as a reflection of societal values (Gerbner, Gross, Morgan, Signorielli, \& Shanahan, 2002), it is worthwhile to understand how youth people engage in socially unaccepted sexual behaviors.

Up to $43 \%$ of Gay people have reported meeting sexual partners through the Internet. The literature review conducted by Natale (2008) supported that gay people are much more likely than heterosexual men to meet their sexual partners through the Internet. And western orientations have been found to be positively associated 
with acceptance of homosexuals (Detenber, Ho, Neo, Malik, \& Cenite, 2010). As Pruitt (2005) found in his research Internet has created a world of Online Prostitution over the vulnerable societies.

In the form of Internet through mobile phone, social media has been the most popular and widely used Internet mode of youth engaging and this refers to media for social interaction, using highly accessible and scalable publishing techniques on the web such as feeds from blogs, status updates, wikis, discussion boards, and other forms of Web 2.0 technology (Wright \& Hinson, 2009). It is well-known that the latest generation of Web 2.0 technologies (blogs, wikis, RSS, etc.) are quickly becoming ubiquitous, offering many unique and powerful information, sharing, and collaboration features which are accessible via the Internet on computers, smart phones, and tablets or through device applications (Grosseck, 2009).

Today's online experience involves new forms of user engagement with the media (Deuze, 2007) that go beyond direct interactions with the media and encircle a set of activities on which audiences' wider meanings are inscribed. Differently from the past passive consumer, today's audiences are more interactive (Ross \& Nightingale, 2003) performing several activities and developing new relationships at the same time in a more engaging way (Livingstone, 2005).

Theory of selective exposure says that people tend to gravitate toward specific types of media content because of certain pre-existing attitudes, value orientations, or personality traits (Zillman \& Bryant, 1985). Going by the premise of selective exposure, it may be that people who hold positive attitudes toward gay men and lesbians will be more inclined to watch attractive contents depicting homosexuality.

Alasuutaari (1999) expresses an interesting possibility that the task of contemporary audience research is to study the whole media culture on which audience activity takes place. This media culture encircles not only traditional commercial audiences analysis that focus on ratings and measurement (Schroder, Droter, Kline, \& Murray, 2003) but also the understanding of what users are actually doing online. One theory states that the cultural experience of a specific media can be treated as the process of involvement and understanding of that media by a specific audience (McQuail, 1997).

According to Bandura's $(1973,1983)$ social learning and cognitive theories, we learn either from experience or observation. One of the ways we can learn is by observing people in films and documentaries. At the same time that we observe behaviors we are also learning scripts, which according to Buckley and Anderson (2006), define situations and guide behavior. Well-known scripts are known as knowledge structures. They further claim that learning is a combination of personal and situational or environmental variables. Input variables can make constructs more accessible in memory; they can influence mood and emotion; and the level of arousal can also have an effect on learning. According to Buckley and Anderson, "behavior is guided by learning, internalizing, and applying scripts" (2006, p. 373). Furthermore, they suggest development of these knowledge structures can change an individual's personality.

(2) Do the changes of human sexuality correlate with the Internet using in Mobile Phone? If so, how does it work in the practice?

In addition to Internet downloaded pornography content using in the mobile phone, e-dating is the most widely seen behavior in the forms of Skype and web cam cyber sexualities. Using Internet through mobile phone for the purposes of sexual entertainment can be seen mostly $52 \%$ in once per a day and $39 \%$ and $27 \%$ in twice and thrice per day respectively. When it is concerned on the various sexual contents that is interested in using Internet is heterosexual interactions are being the maximum by $69 \%$ and Homosexual and Bisexual activities mount by $17 \%$ and $13 \%$ serially. There are $2 \%$ of other sexual behaviors that consisting material and 
animal sexual contents. In the variety of sexual behaviors it is homosexuality that is gradually increasing as the most interesting sexual behavior. And oral and anal sex are the most interesting behaviors in the homosexuality that is determined by the Internet effect. In the Bisexuality, oral and intercourse are the two major sexual behaviors, while in the heterosexuality is much popular in the form of intercourse as being the major sexual behavior. An engaging fact is that the attraction to homosexual behaviors begins under the age category of 14-16 and bisexual behaviors receive in the age category of 20-25.

(3) How does Buddhist rural society really respond to new media cultures? What are the effects of Internet Mobile Phone to human sexuality?

Ever since 1988, when both Richard Gombrich and Gananath Obeyesekere's Buddhism Transformed and George D. Bond's The Buddhist Revival in Sri Lanka both appeared, numerous scholars have attempted to account for the changes in contemporary Sri Lankan Buddhism.

Anthony Giddens's work on modernity helps us to recognize some of these other influences behind the most recent developments in Sri Lankan Buddhism. Briefly, according to Giddens, the intensive modernity that characterizes our world is marked by radical discontinuities from a way of life where knowledge and social organization was dispensed by locally transmitted traditions. As a result, traditional social relations have been lifted out, or "disembedded", from the immediacies of interactions strictly within local contexts and stretched across indefinite spans of space and time, so that persons are freer than ever to disregard local habits and customs and to adopt practices and ideas that have spread across the globe (see Giddens, 1990, pp. 20-22). Buddhism in the face of Modern information, New Media, Liberal Politics has been changing in many dimensions (Berkwitz, 2003) so that even though the spread of popular Buddhist in many ways its impact on humanity to decrease social tension and liberate human mental stress could not be possible with modern social cultural environment.

With global migrations and multi-cultural communities, it is possible for an individual to assume more than one cultural orientation (Benet-Martı'nez, Leu, Lee, \& Morris, 2002; Hong, Morris, Chiu, \& Benet-Martı'nez, 2000). Differing cultural orientations can affect perceptions, memories, and judgment, and shifts in cultural orientation can be influenced by media representations. For example, Hong et al. (2000) found that bicultural people were able to shift between their Asian and Western cultural frames when they were exposed to cultural cues relevant to their respective cultural orientation. Western cultures have often been described as "individualistic and conflict-ridden" whereas Asian cultures place less emphasis on individual rights but more on harmony, family, and community as a whole (Pinches, 1999). However, Sri Lanka has been long in the layers of highly sensational media practice that cover every social and cultural environment from dominant cultural and political establishment.

(4) Why do the rate of crime, murder, sexual problems and other family destructions rapidly increase amidst the most Buddhist religious media and communication society?

Buddhist practice has been originated fundamentally through the pillars of Buddhist thought and precepts. Buddhist theories for practical solutions in the therapeutic treatment in gay and lesbian issues has been widely researched (Blando, 2009; Finucane \& mercer, 2006; Follette \& Linhan, 2004; Ma \& Teasdale, 2004; Mason \& Hargreaves, 2001; Zettle, 2005). As Jones (2003) identified the following sets of core Buddhist concepts:

(1) The four noble truths;

(2) The three signs of being (impermanence, insubstantiality, and dukkha);

(3) The three fires (greed, aggressiveness, and existential delusion); 
(4) Dependent co-origination;

(5) Mutual causality;

(6) The moral precepts;

(7) The noble eightfold path;

(8) Karma.

However, Currently widespread media and communication of Buddhist religious practice have not paid its most essential elements that deeply discuss human nature and its natural science which is highly concerned in the core substance of the Buddhist religion. And at the same time in a much liberal economic and high commercial and consumer society, it is very minimal to concern such real essentialities of Buddhist which, it is immensely popular in petty aspects of religion related to race, ethnicity and cultural differences.

In this, the dominant religious discourse has paid their attention onto such popular market oriented consumerist aspects of Buddhist preaching, no solution to made for the decrease of increasing rate of crime, murder, and sexual depression that are emerging in day to day cross-currents in the society. Moreover, this dominant religious discourse and practices are always having a symbiotic relation with the dominant economic and political sectors; they do not address the real secular burning issues that remain constituently in the Sri Lankan society.

(5) Do widely expanding communication and media of Buddhist religious practices not having relationship with increasing social changes in the facets of sexuality? If so what are the other issues related to sexual changes?

Sri Lanka's media channels are divided along linguistic and ethnic lines, with state-run and private stations offering services in the main languages (Coperahewa, 2009). Even though Coperahewa concerns as the Internet is a growing medium for news and current affairs, and many newspapers have online editions, Internet has been given much attention on pornography contents (TRC-Sri Lanka. 2014) rather than other informational factors. And on the other hand Internet using for pornography and illegal sexual entertainment (E-dating) has been accelerating more than in other south Asian countries (TRC-Sri Lanka. 2014).

Sri Lanka ranks among the nations that have the highest levels of literacy in Asia, considered in the context of its low per capita income. According to figures estimated by UNESCO, in 2001 the literacy rate in Sri Lanka was $91 \%$. The adult illiteracy rate is $9.8 \%$ in Sri Lanka, but it is $36.6 \%$ for South Asia (UNESCO, 2000). Literacy has increased to $91.9 \%$ by 2012 according to central Bank annual report (Sri Lanka, 2013). Many factors contribute to this state of affairs; one of these is the position literacy occupies in the historical and cultural life of Sri Lankans in general and of Sinhalese in particular (Dissanayaka, 1990). However nature of the media literacy is relatively minimal comparison to the expansion and extending of mass media and other forms of new media.

It is estimated that nearly 55 TV channels, 35 Radio channels, and 120 weekend and weed days newspapers including in all three languages; Sinhala, Tamil and English could be conducting in Sri Lanka, which is relatively very high in comparison to population $(20,328,000)$ and land area including inland waters (62705KM2) as per the central Bank annual report 2013 of Sri Lanka. However, the amount of using Internet for awareness and other forms of intelligent factors have been minimal at the high rate of using mobile phone for general entertainment and general informational messaging purposes.

The system of education in Sri Lanka evolved over centuries, originating with an indigenous system of education provided in Buddhist temples (pansala) and pirivenas. A prominent place was given to the 
promotion of literacy under the curriculum of monastic education, no doubt accounting at least in part for the high literacy rate among the population. The sanghas, or Buddhist monks, were the custodians of education and literary activity. At the village level, literate monks taught students in the temple school. However, colonialism brought European style "school education" to Sri Lanka in the 17th century. Its momentum sustained, during the early 19th century, the tradition of literacy and scholarly activity that had undergone a revival in the mid-eighteenth century. The pirivenas were reorganized during the early 19th century, but they were never integrated into the modern education system. In the early 20th century, pirivena education provided training in Buddhist doctrine and oriental languages, mainly Pali, Sanskrit, and Sinhala (Coperahewa, 2009). However the Media Education has implemented in 2009 from grade 9 and it boost to ordinary level and Advanced level school curricula serially in 20011 and 2012 (National Education Institute, Sri Lanka, 2013) so that there is an insufficient media literacy that causes on both media audience and media industry for sensational practices exceeding comprehensive media usage that is expected in the new media society.

\section{Conclusion \& Recommendation}

This study concludes that the expending rate of Internet in Mobile phone has been a platform to present hidden and implicit sexual desires and taste in more liberal manner at the expense of others romantic feeling. This is expressive in more fundamental and rigid religious societies. Even though, the countries which are highly fundamental and rigid in their religion, while they highly emphasis on the so-called well-civilized religious land, it is shown a contradiction in the increasing rate of crime, murder, and social destruction while they talk about a moral and ethical principles of a fundamental religion. This has been phenomenal at the social change catalyzed by Internet in the mobile phone.

This has given a dilemma in the field of sexual behavior over the vulnerable groups. In Sri Lanka, currently increasing social criminal problems and other every form of social unethical and unprofessional incidents and situations are shown as the results of this incompatibility in long driven religious cults when they do not associate the current social conflicts and psychological conflicts in a narrow framework of analysis. In other words, in the dominant religious discourse, it has no solution to current social change. Moreover, in a more new media operated online world as they expand their capacities and strengths delimiting into existing behaviors and social system, vulnerable groups in adolescents and youth play their cultures in a more broad perspective delimiting into existing cultural and moral peripheries so that the traditional sexual behaviors are also disappearing. And implicit and socially unacceptable natural cognitive and perceptional behaviors of sex are flooding into the conventional cultures disastrously. This begins a new conflict over the traditional cultures.

This contradiction is not in its early canons in the Buddhist religion. Diversity and variety of sex and sexual behaviors are fully elucidative in the early Buddhist canon and other parallel sources of early Buddhism, so that the current social and cultural dilemma comes under a pseudo religious discourse. In other words, Modern Sri Lankan widespread popular Buddhist discourse do not deals with the very natural and authentic basic principles of early Buddhist discourses and precepts as well as percepts. In brief, Modern Buddhist rural societies do not remain on the supreme practice of Buddhism.

In this scenario, Internet media through the mobile phone has been activating in its full strengths and capacities delimiting into morals, ethics, good \& bad, well-made. Even though language literacy rate is high, media literacy, which leads to a broad analysis of social and cultural criticism is still in a low level that incompatible with the use and expansion of internet and mobile phone media in Sri Lanka. Lack and absence of 
a new media policy as well as a high discipline made in both from academic and religious discourse has been the stage, where to dance this issue in its full and open manner so that the prevailing sophisticated discourses of religion has not been sufficient to contribute positively for this situation.

\section{References}

Alasuutaari, P. (1999). Rethinking the media audience. London: Sage.

Allen, L. (2013). Sexual assemblages: Mobile phones/young people/school. Discourse: Studies in the Cultural Politics of Education, 36(2), 120-132.

Annenberg Media Exposure Research Group. (2008). Linking measures of media exposure to sexual cognitions and behaviors: A Review. Communication Methods and Measures, 2(1-2), 23-42.

Annual Report-2013. (2013). Central Bank of Sri Lanka. Janadipathi Mawatha, Colombo 01.

Barzilai-Nahon, K., \& Barzilai, G. (2005). Cultured technology: The Internet and religious fundamentalism. The Information Society, 21(1), 25-40.

Berkwitz, S. C. (2003). Recent trends in Sri Lankan Buddhism. Religion, 33(1), 57-71.

Blackwell, C. W. (2008). Men who have sex with men and recruit bareback sex partners on the Internet: Implications for STI and HIV prevention and client education. American Journal of Men's Health, 2(4), 306-313.

Blando, J. A. (2009). Buddhist Psychotherapy with older GLBT clients. Journal of GLBT Family Studies, 5(1-2), 62-81.

Buerkel-Rothfuss, N. L., \& Strouse, J. S. (1993). Media exposure and perceptions of sexual behaviors: The cultivation hypothesis moves to the bedroom. In B. S. Greenberg, J. D. Brown, J. A. Courtright, \& S. J. Baran (Eds.), The acquisition of sexual information by young people (pp. 107-114).

De Silva, W., Karunathilake, K., \& Perera, R. (2009). Patterns of sexual vulnerability among adolescents and youth in SriLanka. Asian Population Studies, 5(1), 41-59.

Deuze, M. (2007). Media work. London: Polity.

Disanayaka, J. B. (1993). The monk and the peasant. Colombo: State Printing Corporation.

Flanagin, A., \& Metzger, M. (2001). Internet use in the contemporary media environments. Human Communication research, 27(1), 153-81.

Freeman-longo, R. E. (2000). Children, teens, and sex on the Internet. Sexual Addiction \& Compulsivity: The Journal of Treatment \& Prevention, 7, 75-90.

Gombrich, R. (1971). Precept and practice: Traditional Buddhism in the rural highlands of Ceylon. Oxford: Clarendon.

Gombrich, R. (1988). Theravada Buddhism: A social history from Ancient Benares to Modern Colombo. London: Routledge.

Gombrich, R., \& Obeyesekere, G. (1988). Buddhism Transformed: Religious change in Sri Lanka. Princeton: Princeton University Press.

Harris, E. J. (2001). Buddhism in war: A study of cause and effect from Sri Lanka, culture and religion. An Interdisciplinary Journal, 2(2), 197-222.

Hasinoff, A. A. (2013). Sexting as media production: Rethinking social media and sexuality. New Media and Society, 15, 449-465.

Ho, S., Detenber, B., Malik, S., \& Neo, R. (2012). The roles of value predispositions, communication, and third person perception on public support for censorship of films with homosexual content. Asian Journal of Communication, 22(1), 78-97.

Jenkins, H. (2006). Convergence culture: Where old and new media collide. New York: NYU Press.

Kent, A. (2009). A Buddhist Bouncer: Monastic adaptation to the ethos of desire in today's Cambodia. Journal of Contemporary Religion, 24(3), 291-303.

Klapper, J. T. (1960). The effects of mass communication. Glence, IL: Free Press.

L'Engle, K. L., Brown, J. D., \& Kenneavy, K. (2006). The mass media are an important context for adolescents' sexual behavior. Journal of Adolescent Health, 38, 186-192.

Livingstone, S. (2005). Media audiences, interpreters and users. In M. Gillespie (Ed.), Media audiences. London: Open University Press.

McQuail, D. (1997). Audience analysis. London: Sage.

Pascoe, C. J. (2011). Resource and risk: Youth sexuality and new media use. Sexuality Researchand Social Policy, 8(1), 5-17.

Peterson, R. A., \& Kahn, J. R. (1995). Media preferences of sexually active and inactive youth. Sociological Imagination, 32, $29-43$. 
Ringrose, J., Gill, R., Livingstone, S., \& Harvey, L. (2012). A qualitative study of children andyoung people and "sexting”. A

Report Prepared for the NSPCC, London: Institute of Education, University of London.

Rodríguez Rust, P. C. (2002). Bisexuality: The state of the union. Annual Review of Sex Research, 13(1), 180-240.

Rompaey, V., Roe, K., \& Struys, K. (2002). Children's influence on Internet access at home: Adoption and use in the family context. Information, Communication \& Society, 5(2), 189-206.

Ross, K., \& Nightingale, V. (2003). Media and audiences: New perspectives. London: Open University Press.

Skoric, M. (2007). Is culture destiny in Asia? A story of a Tiger and a Lion. Asian Journal of Communication, 17(4), 396-415.

Tambiah, S. J. (1992). Buddhism Betrayed? Religion, politics, and violence in Sri Lanka. Chicago: University of Chicago Press.

Taylor, J. (1999). (Post-) Modernity, remaking tradition and the hybridisation of Thai Buddhism. Anthropological Forum: A Journal of Social Anthropology and Comparative Sociology, 9(2), 163-187.

Turner, M. L. S. (2008). Understanding emotions experienced when using a mobile phone inpublic. The Social Usability of Mobile (Cellular) Telephones, 25(3), 201-215.

Wallace, P. (2001). The psychology of the Internet. Cambridge: Cambridge University Press.

Ward, L. M. (2003). Understanding the role of entertainment media in the sexual socialization of American youth: A review of empirical research. Developmental Review, 23, 347-388.

Wei, R., \& Lo, V. H. (2013). Examining sexting's effect among adolescent mobile phone users. International Journal of Mobile Communications, 11, 176-193.

Wickremeratne, A. (1995). Buddhism and Ethnicity in Sri Lanka. Kandy: International Centre for Ethnic Studies.

\section{Appendix}

Table 1

Survey Data Analysis

\begin{tabular}{lcc}
\hline Age category & sample & Percentage $\%$ \\
\hline $14-16$ & 65 & $32.5 \%$ \\
$17-19$ & 35 & $17.5 \%$ \\
$20-25$ & 65 & $32.5 \%$ \\
$26-30$ & 35 & $17.5 \%$ \\
Sample Total & 200 & $100 \%$ \\
\hline
\end{tabular}

Table 2

Survey Data Analysis

\begin{tabular}{lclc}
\hline Age category & sample & Male/Female & Total Percentage $\%$ \\
\hline $14-16$ & 65 & $30 / 35$ & $32.5 \%$ \\
$17-19$ & 35 & $15 / 20$ & $17.5 \%$ \\
$20-25$ & 65 & $30 / 35$ & $32.5 \%$ \\
$26-30$ & 35 & $15 / 20$ & $17.5 \%$ \\
Sample Total & 200 & $90 / 110$ & $100 \%$ \\
\hline
\end{tabular}

Table 3

Survey Data Analysis

\begin{tabular}{lllll}
\hline Age category & Sample & Male/Female & $\begin{array}{l}\text { Mobile Phone Internet and } \\
\text { Computer Internet }\end{array}$ & Total Percentage \% \\
\hline $14-16$ & 65 & $30 / 35$ & $24 / 22$ & $32.5 \%$ \\
$17-19$ & 35 & $15 / 20$ & $13 / 14$ & $17.5 \%$ \\
$20-25$ & 65 & $30 / 35$ & $26 / 28$ & $32.5 \%$ \\
$26-30$ & 35 & $15 / 20$ & $15 / 17$ & $17.5 \%$ \\
Sample Total & 200 & $90 / 110$ & $78 / 81$ & $100 \%$ \\
& & & $39 \% / 40.5 \%$ & \\
\hline
\end{tabular}


Table 4

Survey Data Analysis

\begin{tabular}{lllllll}
\hline Age category & sample & Male/Female & $\begin{array}{l}\text { Mobile Phone } \\
\text { Internet and } \\
\text { Computer Internet }\end{array}$ & $\begin{array}{l}\text { Most interested } \\
\text { internet } \\
\text { content-Education }\end{array}$ & $\begin{array}{l}\text { Most interested internet } \\
\text { content-Entertainment }\end{array}$ & $\begin{array}{l}\text { Total } \\
\text { Percentage } \%\end{array}$ \\
\hline $14-16$ & 65 & $30 / 35$ & $24 / 22$ & $12 \%$ & $28 \%$ & $32.5 \%$ \\
$17-19$ & 35 & $15 / 20$ & $13 / 14$ & $13 \%$ & $29 \%$ & $17.5 \%$ \\
$20-25$ & 65 & $30 / 35$ & $26 / 28$ & $47 \%$ & $24 \%$ & $32.5 \%$ \\
$26-30$ & 35 & $15 / 20$ & $15 / 17$ & $28 \%$ & $23 \%$ & $17.5 \%$ \\
Sample Total & 200 & $90 / 110$ & $78 / 81$ & $100 \%$ & $100 \%$ & $100 \%$ \\
& & $39 \% / 40.5 \%$ & & & \\
\hline
\end{tabular}

